\title{
THIRLWALL YASASI ve MAKROEKONOMİK SONUÇLARI
}

\author{
Gülsüm (Özkan) AKALIN \\ Marmara Üniversitesi, İI.I.B.F., İktisat Bölümü, Yardımcl Doçent Dr
}

\begin{abstract}
In this paper, it is dealt with "Thirlwall's Law" and Balance-of-Patments Constraint Growth Model developed by A. $P$. Thirlwall and their macroeconomic implications. This model is known as an approach to PostKeynesian Growth Models. Therefore, a brief summary of PostKeynesian Theory is held and introduced. Then, sample countries results which are tested for the Law are taken into account.
\end{abstract}

\section{Gİiș}

Bilindiği gibi makroekonomik yönetimin temel amaçlarından birisi de büyümedir. Globalleşen dünya ekonomisinde dişa açık makroekonomik modellerin kısa đönem analizini Mundell-Flemming Modeli'nde bulmak mümkündür. Ancak ulusal ekonomi, bölgesel ekonomi ya da global ekonominin uzun dönem hedefleri belirlenmeden kısa dönem hedeflerine varılmasinda güçlüklerin olacağı açıktır. Bu nedenle, uzun dönem büyüme modelleri de önemlidir.

İktișat literatüründe bu açıdan çekirdeğini Klâsik Teori'nin oluşturduğu arz yanlı büyüme modelleri ile Keynes'ten beslenen talep yanlı büyüme modelleri geliştirilmiştir. James Tobin'nin de belirttiği gibi iki göze sahip olan bizler, olaya talep ve arz cephesi olmak üzere her iki yönden de bakmak zorundayiz [1]. Ancak, bu makalede sadece talep yanl ${ }_{1}$ yaklaşım üzerinde durulacaktır. $\mathrm{Bu}$ da Thirlwall tarafindan, Harrod'un büyüme modelinin genişletilmiş şekli olan ve ihracat güdümlü büyüme modellerine Post-Keynesyen Yaklaşım olarak da sunulan [2,3] Ödemeler Bilânçosu Kısıtına Dayalı Büyüme (The Balance of Payments Constrained Growth-BPC) Thirlwall Modeli ve bunun sonucu olan, Thirlwall Yasası'dir.

Bunun için önce PostKeynesyen Teori hakkında kısaca bilgi verilecektir. Sonra Thirlwall'tn BPC Modeli ve Yasası gelişmiş ve gelişmekte olan ülkeler için geliştirilmiş haliyle açıklanacaktır. Ardından bu konuda son dönemde yapılmış çalışmaların sonuçları üzerinde durulacak ve bunlardan makro ekonomi politika sonuçları çıkarılmaya çalışılacaktır.

\section{POSTKEYNESYEN TEORİ ve TEMEL ÖZELLÍKLERİ}

Post kelimesinin sözlük anlamının "sonra" olmasına dayanarak Keynes sonrasi Keynesyen Teori olarak algılanmaması gereken bir iktisat okuludur. PostKeynesyen Teori, Keynes'in eserlerini yazdiğı dönemde birlikte çalıştığı (örneğin Joan Robinson gibi) arkadaşlarının oluşturdukları [4] ve metodolojik açıdan kendine özgü özellikler taşıyan [5] ve Keynes'in eserlerini en doğru yorumladıklarını iddia eden iktisat okulunun adidrr.

$\mathrm{Bu}$ okul, Keynes'in çok yanlış yorumu olarak kabul ettikleri NeoKlâsik Sentez'e şiddetle karşı çıarlar. Cünkü Keynes'in analizi ile NeoKlâsik Sentez arasında çok önemli metodolojik farklilıklar vardtr [5]. PostKeynesyenler'e göre Keynesyen Devrim'in bu şekideki yorumu devrimin. başlamadan ortadan kalkmasına neden olmuştur [6].

O halde PostKeynesyen İktisat Okulu, bir yandan Keynes'in çok yanlış yorumu olan NeoKlâsik Sentez'e karşı çıkanlar ile diğer yandan Klâsik Sistem'e karşı çıkanların oluşturdukları iktisat okulunun adıdır. PostKeynesyen grubun görüşlerini yansıtan iki süreli yaym bulunmaktadir. Bunlar, Journal of PostKeynesian Economics ve 'Cambridge Journal of Economics'tir [5]. Bu makalede ele aldığımız konu da, son yıllarda bu dergilerde sıkça işlenen konulardan biridir.

PostKeynesyen Teori'yi NeoKlâsik Teori'den ayıran temel özelliklerden bir tanesi zaman boyutudur. PostKeynesyen Teori'ye göre, ekonomik olaylar tarihsel bir süreç içinde ele alınır. Yani, bu teoride geçmiş yılların ekonomik deneyimleri göz önüne alınır ve geçmişten geleceğe doğru bir bakış açısı ile yola çıkılır. Bu zaman boyutu yaklaşımı nedeni ile de dinamik bir özellik taşır. Oysa NeoKlâsik Teori'de böyle bir bakış açısı yoktur. Bu nedenle, NeoKlâsik Teori'de kısmî ya da genel denge analizleri geliştirilmiştir. Bu dà, statik veya karşılaştırmalı statik analize dayanır ve Keynes'in bu şekildeki yorumu olan NeoKlâsik Sentez temelde bu açıdan yanlıştır. Keynes'e haksızlık edilmişstir [5].

Dow bunu her şeyin bilinebildiğini kabûl eden kapalı düşünce sistemi olan, atomizm ve dualizmle tanımlanan Kartezyen-Öklidyen düşüncenin bir sonucu olduğu ve genel denge analizinin bunu en güzel örneği 
olarak gösterilebileceğini ve NeoKlâsik İktisat Teorisi'nin de bu grupta yer aldığını belirtir. O'na göre, PostKeynesyen Teori her şeyin bilinebildiğini kabûl etmeyen açık düşünce sistemi atomizm ve dualizmin ötesinde bir hareket tarafindan karakterize edilen ve genel denge analizini reddeden Babilyen düșünce sistemine uygun düştügünü belirtir.

PostKeynesyen Teori'yi NeoKlâsik Teori'den ayıran ikinci özellik belirsizlik ve beklentiler üzerinedir. Yukarıda sözü geçen Kartezyen-Öklidyen kapalı düşünce sisteminde en küçük yapı taşı olan atomlardan yola çıkılarak, bireyler ele alınır ve bu bireyler, her șey hakkında bilgilenebildikleri için, rasyonel karar alabilme gücüne sahiptir. Geleneksel iktisaţ̧ılar bu açıdan belirsizliği kabul etmezler. Çünkü, Kartezyen-Öklidyen düşüncede varsayllan daha fazla bilgi sahibi olmak belirsizliği azaltırken, Babilyen açık düşünce sisteminde daha fazla bilgi belirsizliği artırır. Nitekim Kuantum fiziği de belirsizliği içerir. Yani, bilgi edindikçe karmaşıklık artmakta, netlik kaybolmakta ve iktisadî olay bulanıklaşmaktadır. Bu anlamda bir belirsizlik Keynes'de ve PostKeynesyen Teori'de mevcutken Geleneksel iktisatçılarda yoktur [5].

$\mathrm{Bu}$ nedenle PostKeynesyen'ler, NeoKlâsikler' in "iktisadî insan" varsayımını reddederler. Bilindiği gibi, iktisadî insan tipi bireylerin yanılmazlığına dayalıdır. Bu açıdan da kaynaklar hep optimal dağllmaktadır. Oysa PostKeynesyen Teori'de beklentiler farklıdır, kararlar farklı alınabilir, gelecek geçmiş̧e alınan doğru ya da yanlış kararların bir sonucu olacaktır. $O$ halde, geleceğin belirsizliği yapılacak uzun vadeli sözleşmelerle ortadan kaldırılmalıdır [7]. $\mathrm{Bu}$ nedenle PostKeynesyen'ler sözleşmelere büyük önem verirler. Bireysel davranıștan daha çok sürü psikolojisinin (animal spirits) hakim olduğunu kabûl ederler.

Bunu en önemli sonucu da NeoKlâsik liktisat'ta olduğu gibi, FIYYAT'm her zaman doğru bir gösterge olamayacağıdır. PostKeynesyen'lere göre, sadece bugünkỉ fiyat gelecek hakkında belirleyici güce sahip değildir. Onlara göre, "ekonomik gelecek fertler tarafindan yaratılır yoksa keşfedilmez". PostKeynesyen Teori'ye göre, hem sektörel talepteki hem de toplam talepteki değişmeler nispi fiyatlardaki değişmeler yerine gelirdeki değişmelere bağlıdır. Bu nedenle, ikâme etkisi yerine gelir etkisine önem verirler [6]. Nitekim aşağıda inceleyeceğimiz ödemeler bilânçosu kusıtına dayahı büyüme modelinde de, ihraç ve ithâl ürünlerinin fiyat esnekliklerinden değil gelir esnekliklerinden yola çılıılmıştır.

\section{THIRLWALL MODELI ve THIRLWALL YASASI}

Thirlwall [8] 1979 yllında, Harrod'un dış ticaret çarpanından kalkarak ödemeler bilânçosu kısıtına dayalı talep yanlı buiyüme modeli geliştirir. O'nun hipotezine göre bir ekonominin uzun dönem ekonomik büyümesi ödemeler dengesi ile sinılıdır. Bu nedenle, Thirlwall Yasası aslında Ödemeler Bilânçosu Kısıtına Dayalı Büyüme Modeli (BPC Modeli) olarak da literatüre yerleşmiştir.

Thirwall modeline başlarken aradığı soru şudur. "Ülkeler arasında neden büyïme farklılıkları vardır?". Bu sorunun cevabını Keynesyen bakış açısı ile incelemek gerektiğini düş̧ünür ve "büyüme oranları farklıdır, çünkü ülkeler arasındaki talepteki büyüme farklıdır" tezinden yola çıkar. O'na göre "açık bir ekonomide büyümeyi sinurlayan temel etken ödemeler bilânçosudur [8].

$\mathrm{Bu}$ modelde ihracat ve ithalat fonksiyonları şöyledir. Burada esas olarak Davidson'un notasyonları kullanılacak ve sonuçlar orijinal makalelerle de desteklenecektir.

$$
\begin{aligned}
& X_{a \Rightarrow}\left(P_{d} / P_{f}\right)^{z} Y^{e r w} \\
& M_{a \Rightarrow}\left(P_{d} / P_{f}\right)^{u} Y^{e a}
\end{aligned}
$$

Burada;

$X_{\mathfrak{a} \Rightarrow}$ A ülkesinin ihracatı,

$\mathrm{M}_{\mathrm{a} \Rightarrow}$ A tilkesinin ithalatı,

$\mathrm{P}_{\mathrm{d}} / \mathrm{P}_{\mathrm{f} \Rightarrow}$ Yurtiçi fiyat düzeyinin yurtdışı fiyat düzeyine orani,

$\mathrm{z}_{\Rightarrow}$ A ülkesinin ihracatına olan talebin fiyat esnekliği,

$U_{\Rightarrow} A$ ülkesinin ithalatının fiyat esnekliģi,

$\underset{\mathrm{a} \Rightarrow}{\mathrm{C}} \mathrm{A}$ ülkesinin ithal talebinin gelir esnekliği,

${ }_{r w \Rightarrow}{ }^{2}$ A alkesinin ihracatına olan talebin gelir esnekliği'dir.

Thirlwall'a göre ${ }^{z}$ ve " küçükse ya da nispî fiyatlar önemli bir değişiklik göstermiyorsa ki uzun dönemde değișmediği kabul edilir, tek fiyat kanunu geçerlidir. Tek fiyat kuralının geçerli olmasını oligopolistik piyasa yapısına bağlayan Thirlwall [2] bu konuda yoğun eleștiri almıştır $[9,10]$. O zaman ikâme etkisi ihmal edilir ve analiz gelir etkisi üzerinde yoğunlaşır. Eşitlik (1) ve (2) ikâme etkileri ihmâl edilerek doğal logaritmik formda yazıldığında;

$$
y_{a}=x / e_{a}
$$

elde edilir. Bu eşitlikte,

$\mathrm{y}_{\mathrm{a} \Rightarrow} \mathrm{A}$ ülkesinin GSMH'sundaki büyüme oran,

$\mathrm{x}_{\Rightarrow} \mathrm{A}$ ülkesinin ihracatındaki büyüme oranı, 
$\mathrm{e}_{\mathrm{a} \Rightarrow} \quad \mathrm{A}$ ülkesinin ithal ürünlerine olan talebin gelir esnekliği'dir.

$\mathrm{Bu}$ (3) no'lu eșitlik Thirlwall'ın orijinal makalesinde şu şekildedir [8].

$$
\mathrm{Y}_{\mathrm{BT}}=\mathrm{x}_{\mathrm{t}} / \pi \text {, }
$$

Burada ,

$\mathrm{Y}_{\mathrm{BT}} \Rightarrow$ Ödemeler bilânçosu kısıtına dayalı uzun dönem büytüme oranı,

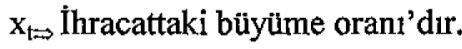

$\pi$, ithalatın gelir esnekliği'dir ve bu eşitlik Thirlwall Yasası olarak kabul edilir. Bu yasaya göre, bir ülkenin uzun dönem denge büyüme oranı ihracattaki artış ile ithalat talebinin gelir esnekligi tarafmdan belirlenir.

Daha sonra A ülkesinin ihracatının artması global büyüme oranına bağlı olacağı için;

$$
\mathrm{x}=\left(\mathrm{e}_{\mathrm{rw}}\right)\left(\mathrm{y}_{\mathrm{rw}}\right)
$$

Burada;

$x_{\Rightarrow} A$ ülkesinin ihracatındaki büyüme,

$\mathrm{y}_{\mathrm{rw} \Rightarrow}$ Dış alem gelirindeki büyüme,

$\mathrm{e}_{\mathrm{rw}} \Rightarrow \mathrm{A}$ ülkesinin ihraç ürünlerine olan dünya talebinin gelir esnekliği'dir.

Yukarıdaki (4) no'lu eşitlik şu şekilde de yazılabilir.

$$
\mathrm{y}_{\mathrm{a}}=\left[\mathrm{e}_{\mathrm{rw}} \cdot \mathrm{y}_{\mathrm{rw}}\right] / \mathrm{e}_{\mathrm{a}}
$$

(5) no'lu eşitlikten çıkan sonuç şudur. Bir ülkenin ödemeler bilânçosu açığı ile karşılaşmaması için tek bir büyüme oranı vardır. $\mathrm{Bu}$ da, sürdürülebilir bir büyüme oranıdır. Bu büyüme orant, (5) no'lu eşitlikte de görü̉düğủ gibi dış dünyanın büyüme oranı ve dış dünyanın söz konusu ülkenin mallarına olan talebin gelir esnekliği ve aynı zamanda ithal mallarının gelir esnekliğine bağlıdır.

Bir adım daha ileri gidilirse ve ihracattaki büyüme oranı ile ithalattaki büyüme oranının birbirine eşit olduğu kabul edilirse;

$$
\mathrm{e}_{\mathrm{rw}} \cdot \mathrm{y}_{\mathrm{rw}}=\mathrm{y}_{\mathrm{a}} \cdot \mathrm{e}_{\mathrm{a}}
$$

elde edilir.

O zaman Davidson'a göre Thirlwall Yasası'na ulaşılmış olur. Bu Thirlwall'ın merkez-çevre ülkeler için geliştirdiği modelin sonucudur [11]. Bu modelde bu eşitlik şu șekildedir.

$$
g_{t} / z_{i}=\alpha / \pi
$$

Bu eşitlikte,

$\mathrm{g}_{t} \Rightarrow$ Bir ülkenin büyüme oranı,

$\mathrm{z}_{\mathrm{t}=}$ Dıs dünyanın büyüme oranı,

$\varepsilon_{\Rightarrow}$ İhraç talebinin gelir esnekliği,

$\pi_{\Rightarrow}$ İthalat talebinin gelir esnekliği'dir.

$$
\left[\mathrm{y}_{\mathrm{a}} / \mathrm{y}_{\mathrm{rw}}\right]=\left[\mathrm{e}_{\mathrm{rw}} / \mathrm{e}_{\mathrm{a}}\right]
$$

(7) no'lu eşitlik Thirwall Yasast olarak isimlendirilir. Bu Yasa şunu belirtir. Bir ülkenin büyümesinin dış dünyanın büyümesine oranı, dış dünyanın söz konusu ülkenin ihraç mallarına olan talebin gelir esnekliğinin o ülkenin ithal mallarının gelir esnekliğinin oranına eşittir.

Eğer $e_{5 w} / e_{a}<1$ ise ve $A$ ülkesinin büyümesi ödemeler dengesi kısıtı ile karşı karşıya ise, o zaman A ülkesinin büyüme oranı dış dünyanı büyüme oranından küçük olmak zorundadır.

$\mathrm{Bu}$ durum gelişmekte olan ülkeler için değerlendirildiğinde çıan sonuç ilginçtir. Bilindiği gibi, azgelişmiş ülkelerin malları olan dış talebin gelir esnekliği düşüktür (Engel Kanunu'na göre). Cünküu bu ülkeler hammadde ihracatçısıdır. İthal ettikłeri ürünlerin ise gelir esneklikleri yüksektir. $O$ zaman azgelişmiş ülkeler için, dünya yalebinin gelir esnekliğinin az gelişmiş ülkelerin gelir esnekliğine oranı birden küçüktür, yani,

$\left[\mathrm{e}_{\mathrm{rw}} / \mathrm{e}_{\mathrm{ldc}}\right]<\mathrm{l}^{2} \mathrm{dir}$.

$\mathrm{Bu}$ durumda ekonomik kalkınma ve ödemeler bilânçosu dengesi piyasa güçlerine burakılırsa, o zaman bu ülkeler yoksulluğa mahkûm edilmiş olacak ve varolan eșitsizlik daha da artacaktır.

Aynı zamanda azgelişmiş ülkelerde kişi başına düșen gelirde, hem yukarıdaki nedenle hem de nüfus artış hızının daha fazla olması nedeni ile açık gittikçe derinleşecektir.

Gelișmiş ülkelerin uzun dönem büyüme oranı \%1 ile \%2,5 arasinda olduğuna göre ve $\left[y_{\text {ldc }}<y_{d w}\right]$ iken $y_{d w}$ 'nin değeri $1<y_{d w}<2,5$ olduğundan, gelişmekte olan ülkeler için sürdürülebilir bir büyümenin gelişmiş ülkelerden daha az olacağı varsayımı ile global ekonominin gelişmesinin hazin sonu hazırlanmış olur.

Davidson'a göre serbest piyasa koşullarında varolan bir Thirlwall Yasası global ekonomi için potansiyel bir korku oluşturmalıdır. $\mathrm{Bu}$ nedenle Davidson'a göre Keynes'in talep yanlı ve paranın yansız olmadtğı görüşü global bir dünya için yeniden ele alınmalıdır. Ancak bu șekilde Thirlwall Yasast'nın serbest piyasa koşullarındaki potansiyel sonuçlarından kaçınılmış olur [2]. 


\section{GELIŞMEKTE OLAN ÜLKELER İÇIN GELISTTIRILMIŞ THIRLWALL MODELI}

Thirlwall 1979 yllındaki ödemeler bilânçosu kısıtına dayalı büyüme modelini gelişmiş ülkeler için test eder ve gelişmekte olan ülkeleri için ise 1982 yllındaki ortak çalıșma ile genişletir [12].

Bu çalışmaya, "1973 ve 1979 petrol krizinde pek çok Orta Doğu ülkesi hiçbir zorlukla karşılaşmadan döviz biriktirirken pek çok gelişmekte olan ülke çok kötü duruma düştü" saptamasından başlarlar ve yine çalışmanın çıkış noktasıı şudur. " Bir ülkenin reel büyüme oranını sınırlayan temel unsur ödemeler bilânçosudur. Çünkü bu ödemeler bilânçosu toplam arzı uyaracak toplam talebin büyümesini sinırlayan en önemli nedendir". Onlara göre, "bütün olarak bir dünya tabii ki ödemeler bilânçosu kısıtı altında olamaz ama bir ülke ya da bir ülkeler grubunun oluşturduğu blok ile dışarıdakilerin böyle bir kısıt altında kalacakları da kesindir"'[12]. Bu cümle Thirlwall'ın 1997 yllındaki makalesinde aynı șekilde tekrarlanır [13]. Fakat, çok da açık değildir. Buradan anlaşılması gereken belki de global bir dünya için ödemeler bilânçosu kısıtından söz etmenin anlamsızlığıdır, ama eğer ayrı ayıı ülkeler varsa ya da bir blok ve dişarıda da bașka ülkeler veya bloklar varsa o zaman böyle bir kısıttan söz etmek gerektiğinin altı çizilmektedir.

Davidson da piyasa güçlerine bırakılmış ve Thirlwall Yasası'nın gelişmiş ve geri kalmış ülkeler arasındaki uçurumu daha da artıracağı endişesini taşımaktadır. Thirlwall-Hussein bunun altını şöyle çizerler. "Pek çok gelişmekte olan ülkenin kaynaklarını tam kullanamadığı ve döviz sıkıntısı içinde oldukları bir durumda böyle bir kısıta tabi tutulmaları beklenemez. Bu doğru değildir". Ve şu gerçekleşen durumdan yola çıarlar. "Son 30 yıldır gelişmekte olan ülkelerin büyümeleri gelişmiş ülkelerinkinden farklı olduğuna göre bunu nasıl gerçekleştirmişlerdir". Ve yine Onlara göre, bu farklılığı "sermaye birikimi, emek arzı, teknolojik gelișme kısmen açıklayabilir". Yani onlara göre, arz yanlı bir açıklama bu büyümeyi tam olarak açıklayamaz [12].

Yaptıkları saptama, "gelişmekte olan ülkeler sık sık cari açıkla karşılaşıyorlar ve bunu sermaye girişi ile finanse ediyorlar ve bu sermaye girişi de daha hızlı büyümelerine neden oluyor". Eğer bu doğruysa basit büyüme kuralı uzun dönem büyüme performansının iyi bir belirleyicisi olmaktan çıkacak, büyüme sermaye girişine bağlı olacaktır. Bunun üzerine sermaye akımını da içeren modeli geliştirirler ve bu modelde de nispî fiyatların değişmediği varsayılır. Model dış açığın olduğu ve bunun sermaye girişi ile kapatılmış olduğu varsayımı ile başlar.
Şu şekilde

$$
\mathrm{P}_{\mathrm{dt}} \mathrm{X}_{\mathrm{t}}+\mathrm{C}_{\mathrm{t}}=\mathrm{P}_{\mathrm{f}} \mathrm{M}_{\mathrm{t}} \cdot \mathrm{E}_{\mathrm{t}}
$$

Bu eşitlikte,

$\mathrm{X}_{\mathrm{t} \rightarrow}$ ihracat hacmi,

$\mathrm{Pd}_{t} \Leftrightarrow$ İhraç ürünlerinin yurtiçi fiyatı,

$\mathrm{M}_{t \rightarrow}$ İthalat hacmi,

$P_{\mathrm{f} \rightarrow}$ İthal ürünlerinin dış fiyatı,

$\mathrm{E}_{\mathrm{t} \Leftrightarrow}$ Döviz kuru (yabancı paranın yurtiçi fiyatı olarak),

$\mathrm{C}_{\mathrm{t} \Rightarrow}$ Yurtiçi para cinsinden ölçülen sermaye akım değeri'dir.

Modelin ayrıntısına girmeden sonuç ẗzerinde durmak yeterli olacaktır.

$$
\mathrm{Y}_{\mathrm{B}}^{*}=\left[\mathrm{C} / \mathrm{R}\left(\mathrm{p}_{\mathrm{dt}}+\mathrm{x}_{\mathrm{t}}-\mathrm{c}_{\mathrm{t}}\right)\right] / \pi
$$

Bu eşitlikte,

$\mathrm{Y}_{\mathrm{B}} \Rightarrow$ Sermaye girişini de içeren uzun dönem denge büyüme orani,

$\mathrm{C} / \mathrm{R}_{\Rightarrow}$ Toplam gelirin oranı olarak sermaye,

$\mathrm{p}_{\mathrm{dt}}+\mathrm{x}_{\mathrm{t} g}$ İhracat gelirlerinin artış oranı,

$c_{\mathfrak{l}}$ Sermaye girişinin artış oranı,

$\pi_{\Rightarrow}$ İthalatın gelir esnekliği,

$\mathrm{x}_{t} \Leftrightarrow$ İhracat hacminin artış oranı,

$\mathrm{p}_{\mathrm{d} t=}$ İhraç ürünlerinin yurtiçi fiyat artış oranı'dır.

Yukarıdaki modelde, sermaye girişindeki artış oranımın $\left(c_{t}\right)$ ihracat gelirlerindeki artıs oranından $\left(p_{d_{t}}+x_{t}\right)$, büyük ya da küçük olmasına göre Thirlwall Yasası'nın açıklayıcı olup olmadığına karar verilecektir.

Şöyleki;

$c_{t}-p_{d}>x_{t}$, ise model belirleyici değil, yani Thirlwall Yasası'nın işlediğini söylemek zorlaşır.

$c_{t}-p_{d t}=0$, ise etkisiz, yani tahminin yasayl destekleme gücü zayıf,

$c_{t}-p_{d t}<x_{t}$, ise ödemeler bilânçosu kısıtı kuralı çok iyi işler, yani Thirlwall Yasası en iyi açıklayıcı güce sahip olacaktır. 


\section{SON DÖNEM ÇALIŞMALARININ DEĞERLENDİRILMESI}

Thirlwall'a göre, toplam talebi belirleyen tüketim, yatırım, devlet harcamaları ve ihracat bileşeni içinde ithalat için gerekli olan dövizi sağlayacak en önemli bileşen ihracattır. Ülkeler arasındaki büyüme oranı farklılıklarımı uzun dönem performansları açısından ortaya koymaya amaçlayan Thirlwall'a göre kısa dönem dış açıklar zaten kısa dönem sermaye girişleri ile finanse edilebilir. İşte tam da bu nedenle dıs açıklar sürekli hale gelir ve bu açık yurtiçi gayrisafi millî hasılanın belli bir oranını aşmaya başlarsa o ülke için tehlike çanları çalmaya başlamış olur. Böyle bir durumdaki ülke de uluslararası finans topluluğunun yaptırmmları ile karşı karşıya kalır. Sürekli dış açıkları sürekli sermaye girişi ile kapatmak mümkün değildir. Ayrıca dış ticaret hadlerini düzeltmek ya da reel döviz kuru dalgalanmaları ile bu açı̆̆ı kapatma girişimleri de uzun dönem itibarı ile sonuç vermez. Thirlwall'a göre, bunlar zaten uzun dönemde istikrarIıdır. Devalüasyonlar sorunu çözmede kalıcı bir etkiye sahip değildir [13].

Bunun için ülkelerin ihracat hacmini artırmaları ve bununla birlikte ithalatın gelir esnekliǧini düşürücü yönde önlemler almaları uygun olacaktır ya da ithalatın gelir esnekliği düşürülemiyorsa ihracatı artırıcı yönde politikalar izlemeleri veya gelişmekte olan ülkelerin gelir esnekliği yüksek ihraç ürünlerine yönelmeleri gerekmektedir.

$\mathrm{Bu}$ modelde, fiyat esneklikleri yaklaşımı uzun dönem itibarı ile reddedilir. Önemli olan ihraç mallarının gelir esnekliği ile ithal mallarının gelir esnekliğidir. Bunlar da, ihracat yapılan ülkenin gelir düzeyi ve sizin ülkenizin gelir düzeyi ile yakından ilgilidir. Bu durumda, ticaret yapan ülkelerin gelir düzeyleri ticaretin seyrini belirleyecektir. Daha doğrusu, bir ülkenin kendi gelir düzeyindeki değişmeler kadar dış dünyanın gelir düzeyindeki değişmeler de $o$ derece önemli olmaktadır.

Thirlwall Yasası, bir ülkenin gerçekleşen büyüme oranını uzun dönem büyüme oranından sapma göstermemesi gereğini vurgular. Bu konuda yapılan yani yasanın sınanması için yapılan en fazla çalışma A.B.D. üzerinedir. Model, ózellikle sabit döviz kuru sisteminin geçerli olduğu 1950-1974 yılları arası ile 1974 yılı sonrası esnek döviz kuru rejiminin geçerli olduğu dönem için ayrı ayrı test edilir. Örneğin, Hieke 1950-1966 ve 1967-1990 yılları arası için yaptığı çalışmada ilk periodda gerçekleşen büyüme oranı ile ödemeler bilânçosu kısıtına ait uzun dönem denge büyüme oranının bire bir örtüştügünü, ikinci period da ise ihracatta büyük artış olmasına rağmen reel gelirde yavaşlama olduğunu ortaya koyar. Bunun nedenini, ithal talebinin yükselmiş olmasina bağlamaktadır [14]. A.B.D.'nin 1986 yılı sonrası yaşadığı dış açıklı yılların, bu ülkenin tarihinde en fazla dış açık verdiği yıllar olduğu belirtilmektedir. Bu dış açıklar sermaye girişi ile kapatılmıştır. Ancak bu periodda bile, gerçekleşen büyüme ơranı ile ödemeler bilânçosu kısıtına dayalı uzun dönem denge büyüme oranı arasındaki sapmanın \%1'den az olduğu belirtilmektedir.

Ateşoğlu'nun A.B.D. için 1955-1990 arası için yaptığı ilk çalışmasında sonuçların Thirlwall Yasası'nı desteklediğini ortaya koymaktadır [15]. Ayrıca 1995 yilındaki çalışmasında A.B.D.'nin son 10 yildaki yavaşlamasının nedenini açıklamak için Thirlwall Yasası'nı kullanmıştır. Bu çalışmaya göre 1947-1973 ile 1974-1992 olmak üzere iki ayrı dönemleme yapmış ve bu iki dönem için iki ayrı ithalat fonksiyonu elde etmiş ve ikinci dönemde ithalatın gelir esnekliğinin yükseldiğini saptamıştır. O'na göre, son 10 yıldaki yavaşlamanın gerisinde ithalatta meydana gelen bu yapısal değişmenin olduğu sonucuna varmaktadır [16]. Ardından 1997 yılındaki çalışmasında [17], 1929-1994 yılları arasında ayrıştırılmış dönemlemeler yaparak uluslararası para rejiminin bu modelin uygunluğunun test edilmesinde öneminin altı çizilmektedir. O'na göre 1931-1974 sabit döviz kuru rejiminin uygulandığı periođda A.B.D'de otoritelerin toplam talep politikası ile dış dengenin sağlanmasina yönelmiş ve başarılı olmuşken, 1974-1994 aralı̆ında uygulanan esnek döviz kuru rejimi döneminde bu politikadan vazgeçmişler ve dış dengenin sağlanması görevini döviz kuru değişmelerine bırakmışlardır. Ancak döviz kuru değişmeleri dış dengeyi sağlayamamış ve açıklar sermaye girişleri ile kapattlmaya çalışılmıştır. Artan dış açıkların bu şekilde kapatılma girişimi de A.B.D. için faiz yükü getirmiştir. Ateşoğlu'na göre bu şekilde bir politika A.B.D. ekonomisine ileride tehdit oluşturacaktır. Ödemeler bilânçosu açılarının kapatılmasında, özellikle esnek döviz kuru rejimi dönemleri itibarı ile bakıldığında dı̧̧ açıkların döviz kuru değișmeleri ile giderilmediğini aksine artan sermaye akımları tarafından finanse edildiğini ortaya çıkarır. Ateşoğlu'na göre, A.B.D.'nin gelecekteki net diş varlığındaki yıpranmayı azaltmasının tek yolu ödemeler bilânçosu fazlası verme yolunda girişimde bulunması ve uzun dönemde ihracat performansı ile reel gelir bağlantısının koparıımaması gerektiğidir.

Barram 1970-1985 yılları arası için İtalya, Almanya, İngiltere, Fransa, A.B.D., Kanada ve aralarmda Türkiye'nin de bulunduğ 19 ülkeyi kapsayan çalışmasında Thirlwall Yasası'nı destekleyici bulgulara ulaşmış̧ır [18]. O'na gốre açık bir ekonomide ekonomi yönetimi için Harrod'un dış ticaret çarpanı en uygun göstergedir. Başarılı bir ekonomi politikası ihracatın gelir esnekliğini artırmayı ve/veya ithalatın gelir esnekliğini azaltmayı gerektirir. Böyle bir durumda dış dünya talebindeki hızlı bir artış, o ülkenin uzun dönem ödemeler bilânçosu dengesinden sapma yaratmaksızın büyümesini sağlar. Ayrıca 1991 yılında Barram'ın Dempster'la yaptığı ortak çalışmada bu kez 11 Asya ülkesi için modeli sınar ve bulguların Thirlwall'ın yaklaşımını desteklediğini belirtilir [19]. O'na göre gelişmekte olan ülkeler gelişmiş ülkelere göre daha az ödemeler bilânçosu kısıtı altındadır. Bunun nedenini Barram, ihracatın gelir esnekliğinin kişi 
başına gelir düzeyi ile negatif ilişkiye sahip olması şeklinde açılarken [20], Thirlwall bu konuda daha dikkatli olunması gerektiğinin altını çizer. Thirlwall'a göre, ihracat talebinin gelir esnekliği, ülkelerin ilksel ürün ihracatından hafif sanayi ürünlerine doğru kayışı ile yükselir sonra zengin ülkelerin (A.B.D., İngiltere gibi) modası geçmiş sanayi yapılarını kaldırması ile de azalır [13]. Baıram'a göre ithalatın gelir esnekliği ile kişi başına gelir düzeyi arasındaki ilişki çok önemsizdir. Bu Thirlwall'a göre şaşırtıcı değildir. Çünkü pek çok gelişmekte olan ülkede tarifeler, kotalar ve tarife dişı engeller vardır ve bunların varlığı da ithalatın gelir değişmelerine olan duyarlılığını azaltır.

Korumaların olmadığı duruma göre yapılmış çalışmaya göre ithalat talebinin gelir esnekliğinin fakir ülkelerde zengin ülkelerden çok yüksek olduğunu ortaya konmuştur [21].

Baıram'm 30 OECD ülkesi için vaptığı en son çalışmaya göre, Kanada ve Japonya hariç tüm gelişmiş ülkelerin ihracatının gelir esnekliği ithalatın gelir esnekliğinden küçüktür. Bu durum söz konusu ülkelerin dünya ekonomisinin genişleme evresinde dış ticaret dengelerinin kötüleşeceğini, daralma evrelerinde ise iyileşeceğini gösterir [22].

McCombie de, en son ekonometrik modellerle açıklanmış bütün çalışmalan kritize eder ve bu çalışmaların sonuçlarına göre ve yine A.B.D., Ingiltere ve Japonya için gerçekleşen çıtı düzeyi ile uzun dönem ödemeler bilânçosu kısıttna ait denge çıtı dïzeyi arasında birebir ilişkinin olduğunun altını çizer [23].

Gelişmekte olan ülkelerde yaşanan krizlerden sonra modele olan ilgide artış gözlenmektedir. Örneğin sermaye girişleri ile finanse edilen diş açıkların dış borçlanmayı artırdığını, bunun üzerine bir ülkenin gerçekleşen büyümesinin uzun dönem ödemeler bilânçosu kısıtının belirlediği büyüme oranında sapma göstermemesi gerektiği vurgulanmaktadır. Bu anlamda Thirlwall'ın modeli (Thirlwall-Hussein modeli) bir adım daha genişletilerek yaşanan krizlere yol açılmaması için uzun dönem büyüme performansının makroekonomik politika yapıcılarına yol gösterici olması açısından büyük öneminin olduğunun altı çizilir [24].

Guatemala, Kosta Rika, Nikaragua; El Salvador ve Honduras için yapılan ekonometrik çalışmada ilk üç ülkenin Thirlwall Yasası'nı desteklediğini, son ikisinin ise Thirlwall-Hussein'in gelişmekte olan ülkeler için geliştirdikleri modele uygun sonuçlar verdiği belirtilmektedir. Yani son iki ülkede sermaye hareketlerinin büyümeyi daha iyi açıkladığı sonucuna varılmaktadir [25].

Uluslararası rekabet açısından konuya yaklaşan Blecker, NeoKlâsik'lerle PostKeynesyen'ler arasındaki farkı Thirlwall Yasası'ndan faydalanarak açıklar. NeoKlâsik'ler maliyetler ve fiyatlar açısından rekabete. yaklaşırken PostKeynesyen'ler fiyat dıșı unsurları dikkate alırlar. Yani rekabete gelir esneklikleri açısından yaklaşırlar [26].

Uluslararası rekabette NeoKlâsik'ler yurtiçi kaynaklar, maliyetler ve fiyatlara önem verir ve bunun için reel döviz kuru değişmelerini önerirken, PostKeynesyen'ler tam bunun tersini savunurlar. PostKeynesyen'lere göre, rekabeti açıklayan unsur ülkelerin ihracat ve ithalatlarının gelir esneklikleridir. Bu anlamda da reel döviz kuru değişmelerinin rekabeti sağlayabileceği görüşüne karşı çıkarlar.

Blecker, bu iki görüşten hangisinin daha açıklayıcı olduğu üzerine bir çalışma yapar. Thirlwall'ın modelini bu anlamda genişletir, ödemeler bilânçosu kısıtına daha rahatlatıc bir boyut getirir ve tüm dünya toplam talebindeki ödemeler bilânçosu kısıtından kaynaklanacak problemleri gidermede ortak çözümler üretmeleri gerektiğini savunur. O'na göre, NeoKlâsik'leri önerisi olan karşılıklı devalüasyonlar, ücret kısıcı politikalar sürekli bir kazanç sağlamaz aksine uluslararası işbirliğini sarsar. Genişleyici makro politikalar tüm ülkeler için daha iyidir. Artan dış gelir, ihraç mallarınm gelir esnekliginini artırma ile aynı etkiye sahiptir. $O$ halde ödemeler bilânçosu kısıtınm genişletilmesi için gerekli olan ihraç mallarının gelir esneklig̈inin artırılması ile aynı etkiye sahip olacaktır. Dış ülkenin gelirinin artması gerekliliği, ülkeler arasında rekabetten çok işbirliğini gerektirir. $\mathrm{Bu}$ nedenle de, komşuyu fakirleştiren devalüasyonlar, ücretleri baskı altında tutucu daraltıcı politikalar yerine miktar esaslı politikalar gütmek daha yerinde olacaktır. O'na göre, küçük ya da büyük bir ülke için NeoKlâsik'lerin savı olan kaynak kısıtının bağlayıcılığı yoktur. Önemli olan o ülkelerin mal ve hizmetlerine yönelen taleptir [26]. Benzer sonuçlara başka bir çalışma ile de ulaşılmıştır [27].

Thirlwall Yasası Îspanya için 1965-1993 aralığında test edilir ve sonuçlar yasayı destekler yani büyümenin ödemeler bilânçosu kısıtına dayalı olduğu, arz yanlı olmadığı sonucuna varılır [28].

Lâtin Amerika özellikle Arjantin, Meksika, Brezilya ve Kolombiya için Thirlwall Yasası'na göre yapılan çalışmada bu ülkelerde 1980'lerden sonra uzun dönem denge büyüme oranının azalış yönünde seyrettiği saptanır. Özellikle Meksika'da 1982 ve 1995 krizlerinin açıklanmasında da bu modelden faydalanılır. Yazarlara göre Meksika için uzun dönem büyüme oranından ayrılması bu krizlerin temel nedenidir. Hesaplarma göre Meksika'da 0,45 olmasi gereken ithalat talebinin gelir esnekliğinin 1,30 olması krizi doğurmuştur [29].

Ayrıca Brezilya (1955-1997) için yapılan başka bir çalışmada büyümenin dişsal faktörlere uydugu ve uzun süre hızlı büyümenin mümkün olamayacağı sonucuna varilır [30]. 


\section{MAKROEKONOMIKK SONUÇLAR}

1) Thirlwall Modeli her bir ülkenin uzun dönem dış ticaret dengesini sağlamaları gereğini vurgular. Yani, her bir ülkenin uzun dönem büyüme oranı vardır ve bunu da belirleyen NeoKlâsik'lerin kabûl ettiği gibi o ülkenin kaynak donanımı, teknoloji düzeyi değil aksine bunları harekete geçirecek olan toplam taleptir. Bu toplam talebin bileşenleri ise, iç ve diş taleptir. Toplam talebi oluşturan unsurlardan tüketim, yatırm, devlet harcamaları ve ihracat bileşeni içinde ithalatın gerektirdiği dövizi sağlayacak olan ihracattır. $O$ halde ihracat hacmindeki artış ile ithalatın gelir esnekliği bir ülkenin uzun dönem büyuime oranının temel belirleyicisidir.

2) Dış dengesizlik halinde devalüasyonlardan kalıcı çözüm beklemek yanıltıcıdır. Sürekli dıș açıkların kapatılmasında fiyat ve döviz kuru değişmelerinden fayda beklenmemelidir.

3) Sürekli dıș açık veren ullkelerin dış dengesinin kısa dönemli sermaye girişleri ile kapatılması mümkündür. $\mathrm{Bu}$ durum özellikle gelişmekte olan ülkelerin büyümelerinde belirleyici bir role sahiptir. Ancak, dış açıkların süreklilik göstermesi ve dış borç sarmalına girilmesi, bu ülkeleri uluslararası finans kurumlarının (örneğin IMF) baskısı altında bırakmaktadır.

4) Asıl altı çizilmesi gereken nokta, her bir ülkenin ayrı ayrı ele alınışının global dünya açısından sorun yaratacağını, bu nedenle tek bir ülkeyi değil tüm global ihracatın global ithalata eşitlenmesi gerektiği ve bu açıdan global işbirliğinin gerekli olduğudur. Thirlwall Yasası'nın ödemeler bilânçosu kısıtına dayalı modelinin bu kısıtı daha gevşetecek şekilde geliştirilmesi ve NeoKlâsik'lerin ücretleri baskı altına almayı ve daraltıcı makroekonomik politikaların aksine genişletici makroekonomik politikaların global ekonomi açısından daha uygun sonuçlar vereceği vurgulanmaktadır.

5) Gelişmekte olan ülkelerin sürdürülebilir kalkınması ödemeler bilânçosu kısitına dayalı büyümesinin bu ülkelerin fakirliğini daha da artıracağı, bu nedenle de piyasa koşullarına bırakılmaması gerektiğinin altını çizmek gerekir.

6) Thirlwall Yasası ve Engel Yasası veri iken, dünya ekonomisinin genişlemesinin, gelişmiş ülkelerin diş ticaretleri aleyhine ve gelişmekte olan ülkelerin ise lehine, daralmasının ise bunun tam tersi sonuçlar vereceği belirtilmektedir. $O$ halde, bu saptamaya göre ekonomik krizlerden kazançlı çıkacak olan gelişmiş allkeler olacaktır.

7) Bu modelde üstü örtük olarak esnek döviz kuru sisteminin dış dengeyi sağlayacağı görüşüne karşı görtiş vardır. Dış dengenin sağlanması da devlet müdahalesini gerektirir.

\section{SONUC}

1979 yilında Thirlwall tarafindan Harrod'un diş ticaret çarpanından yola çıkılarak geliştirilen Ödemeler Bilânçosu Kısıtına Dayalı Büyüme Modeli ve bu modelden çkarılan Thirlwall Yasas1, 1982 yılında gelişmekte olan ülkeler için ve 1983 yllında merkez-çevre modelleri ile geliştirilmiștir. Son dönemde de modelin işleyişine ilişkin çalışmalar yoğunluktadır ve ayrıca Yasa ülkeler bazında en son istatistiksel ve ekonometrik yöntemlerle sinanmaktadır.

Thirlwall Yasası bir ülkenin büyümesini dıș ticaret dengesine bağlar. Bir ülkenin sürdürülebilir büyümesinin uzun dönem denge büyüme oranindan sapma göstermemesi gerektiğini öngörür. Sürekli dış açıkların sürdürülemez olduğunu ve bu açıklarmn döviz kuru değişmeleri ile düzelmesini beklemenin sonuç vermeyeceğini makro ekonominin talep yanlı politikalarla yönlendirilmesi gerektiğini vurgular. 


\section{YARARLANILAN KAYNAKLAR}

[1] FROYEN, Richard T., Macroeconomics, Theories, and Policies, Upper Saddle River, 1996, s.4I6.

[2] DAVIDSON, Paul, PostKeynesian Macroeconomic Theory, Cambridge, 1994.

[3] BLECKER, Robert A., "The Diminishing Return to Export-Led Growth", http: /I www.cfr.org/ public/pubs/blecker-Diminishing-paper.pdf, 2, 2000.

[4] ÇAKMAK, Ahmet, Ortodoks Makro Íktisada Giriş, İstanbul, 1997, s.24.

[5] DOW, Sheila C., The Methodology of Macroeconomic Thought, Cheltenham, 1998, ss.18,19,76-80.

[6] SAVAS,, Vural F., Íktisatın Tarihi, İstanbul, 1997, ss.922948.

[7] PAYA, Merih, Makro İktisat, İstanbul, 1997, ss.262-263.

[8] THIRLWALL, A. P., "The Balance of Payments Constraint As An Explanation of International Growth Rate Differences", Banco Nazionale Del Lavoro, No. 128, March 1979.

[9] McGREGOR, Peter G.; SWALLES, J. K., "Professor Thirlwall and Balance of Payments Constraint Growth", Applied Economics, 17, 1995.

[10] THIRLWALL, A.P., "Balance of Payments Constraint Growth: A Reply to McGregor and Swalles", Applied Economics, 1986.

[11] THIRLWALL, A. P., "Foreign Trade Elasticies in CenterPeriphery Models of Growth and Development", Banco Nazionale del Lavoro, No.146, Sept. 1983.

[12] THIRLWALL, A. P.; HUSSAIN, M. Nureldin, "The Balance of Payments Constraint, Capital Flows and Growth Rate Differences Between Developing Countries", Oxford Economic Papers, 34, 1982, ss.498-510.

[13] THIRLWALL, A.P., "Reflections on the Concept of Balance of Payments Constrained Growth, Journal PostKeynesian Economics, Spring, Vol.19, No.3, 1997, s.384.

[14] HIEKE, Hubert, "Balance of Payments Constrained Growth; A Reconsideration of the Evidence for the U.S. Economy", Journal of PostKeynesian Economics, Vol.19, No.3, Spring 1997, ss.313-326.

[15] ATEŞOĞLU, H. Sornmez, "Balance of Payment Constrained Growth: Evidence From United States", Journal of PostKeynesian Economics, Vol.15, No.4, Summer 1993, ss.507-514.

[16] ATEŞOĞLU, H. Sönmez, "An Explanation of the Slowdown in U.S. Economic Growth", Applied Economics Letters, 2, 1995, ss.91-94.

[17] ATEŞOĞLU, H. Sönmez, "Balance of Payments Constrained Growth Model and Its Implications for United States", Journal of PostKeynesian Economics, Vol.19, No.3, 1997, ss.327-336.

[18] BAIRAM, Erkın I., "Balance of Payments, the Harrod Foreign Trade Multiplier and Economic Growth: The
European and North American Experience, 1970-1985", Applied Economics, 20, 1988, ss.1635-1642.

[19] BAIRAM, Erkm I.; DEMPSTER, Georgina J., "The Harrod Foreign Trade Multiplier and Economic Growth in Asian Countries", Applied Economics, 23, 1991, ss.1719. 1724.

[20] BAIRAM, Erkin I., "Income Elasticities of Exports and Imports: A Re-Examination of the Empirical Evidence", Applied Economics, 25, 1993, ss.71-74.

[21] HUSSAIN, M., "The Balance of Payments and Growth", African Development Report, (African Development Bank), 1995, ss.498-510.

[22] BAIRAM, Erkin, I., "Levels of Economic Development and Appropriate Specification of the Harrod Foreign-Trade Multiplier", Journal of PostKeynesian Economics, Vol.19, No.3, Spring 1997, ss.337-345.

[23] McCOMBIE, John S. L., "On Emprics of Balance of Payments Constrained Growth", Journal of PostKeynesian Economies, Vol.19, Spring 1997, ss.345376.

[24] MARENO-BRID, Juan Carlos, "On Capital Flows and the Balance of Payment Constrained Growth Model", Journal of PostKeynesian Economics, Vol.2 I, No.2, Winter 199899, ss.283-299.

[25] MARENO-BRID, Juan Carlos; PERES, Estaban, "Balance of Payments Constrained Growth in Central America: 1950-96", Journal of PostKeynesian Economics, Vol.22, No.1, Fall 1999, ss.131-148.

[26] BLECKER, Robert A., "International Competitiveness, Relative Wages, and the Balance of Payments Constrained", Journal of PostKeynesian Economics, Vol.20, No.4, Summer 1998, ss.495-527.

[27] ALONSO, Jose A.; GARCIMARTIN, Carlo, "A New Approach to Balance of Payments Constrained: Some Emprical Evidence", Journal of PostKeynesian Economics, Vol.21, No.2, Winter 1998-99, ss.259-282.

[28] LEON-LEDESMAN, Miguel, A., "An Application of Thirlwall's Law to the Spanish Economy", Journal of PostKeymesian Economics, Vol.21, No.3, Spring 1999I, ss. $431-440$.

[29] LOPEZ, Julio G.; CRUZ, Alberto B., " 'Thirlwall's Law' and Beyong: The Latin American Experience", Journal of PostKeynesian Economics, Vol.22, No.3, Spring 2000, ss.259-282.

[30] JAYME, Jr. Frederico, "Balance of Payments Constrains: A Study for the Brezilian Economy", http://www.iaes. org/conferences/past/montreal-48/prelim-program/f141/jayme-htm 